\title{
Importance of Biosurfactant in Food Industry
}

\author{
Ranasalva. $N^{* 1}$, Sunil. $R^{2}$, Poovarasan. $G^{2}$ \\ ${ }^{1}$ Assistant Professor, Vanavarayar Institute of Agriculture, Manakadavu, Pollachi, \\ ${ }^{2}$ III B.Sc Agri. Vanavarayar Institute of Agriculture, Manakadavu, Pollachi,
}

\section{Introduction}

Surfactants are amphiphilic compounds containing both hydrophobic (nonpolar) and hydrophilic (polar) moieties that confer ability to accumulate between fluid phases such as oil/water or air/water, reducing the surface and interfacial tensions and forming emulsions they have a broad spectrum of applications, from everyday tasks such as washing the dishes to advanced oil recovery operations. The global market for surfactants is approximately 8 million tonnes per annum with a total value of $£ 7.1 \mathrm{~b}$. The majority of this demand is met with surfactants obtained from non-renewable oil based feedstocks. An alternative route of surfactant production exists in nature in the form of microbes capable of producing surfactants. Microbially produced biosurfactants are characterised by both their chemical composition and microbial origin and can perform many tasks for which traditional petrochemical or oleochemical surfactants are currently used. (Deleu \& Paquot, 2004).

Biosurfactants are a group of microbial molecules identified by their unique capabilities to interact with hydrocarbons. Biosurfactants have also found utility in fields such as environmental bioremediation, food processing and pharmaceuticals. An interesting example of a biosurfactant is the heptapeptide surfactin, a metabolite of Bacillus subtilis BBK006. Surfactin is highly surface active and exhibits antibacterial, antiviral and antitumor behaviour. The surface activity properties make surfactants one of the most important and versatile class of chemical products, used on a variety of applications in household, industry and agriculture Biosurfactants (bioemulsifiers) are a structurally diverse group of surface-active molecules synthesized by microorganisms. Biosurfactants can successfully replace synthetic surface active substances in modern ecologically safe technologies. Rhamnolipids from Pseudomonas aeruginosa, surfactin from Bacillus subtilis, emulsan from Acinetobacter calcoaceticus and sophorolipids from Candida bombicola are some examples of microbial-derived surfactants (Mohan, Nakhla, \& Yanful, 2006).

When compared to conventional synthetic surfactants, the biosurfactants have some peculiar characteristics (Bognolo 1999)

- Large and complex structure

- Higher biodegradability and lower toxicity

- Lower CMC and higher surface activity

- Superior ability to form molecular assembly and liquid crystal

- Biological activity (antimicrobial, antitumor, etc.)

- Stability to extremes conditions of $\mathrm{pH}$, salinity, and temperature

- Biosurfactants can be produced from renewable substrates by biotechnological processes

Moreover, an increasing consciousness among consumers demands for reducing the use of artificial or chemically synthesized compounds by replacing it for more natural food ingredients and additives. Despite the advantages demonstrated by biosurfactants, few reports are available regarding their use on food products and food processing (Shepherd, Rockey, Sutherland, \& Roller, 1995).

\section{Classification of Biosurfactants}

Biosurfactants are generally categorized mainly by their chemical composition and microbial origin. Rosenberg and Ron16 suggested that biosurfactants can be divided into low- molecular-mass molecules, which efficiently lower surface and interfacial tension, and highmolecular mass polymers, which are more effective as emulsion-stabilizing agents. The major classes of low-mass surfactants include glycolipids, lipopeptides and phospholipids, whereas high-mass surfactants include polymeric and particulate surfactants. Most biosurfactants are either 
anionic or neutral and the hydrophobic moiety is based on long-chain fatty acids or fatty acid derivatives, whereas the hydrophilic portion can be a carbohydrate, amino acid, phosphate or cyclic peptide

Table 1. Major biosurfactant classes and microorganisms involved

\begin{tabular}{|c|c|c|}
\hline Major class & Sub class & Microorganism \\
\hline Glycolipids & $\begin{array}{l}\text { Rhamnolipids } \\
\text { Trehalose lipids } \\
\text { Sophorolipids } \\
\text { Mannosylerythritol lipids }\end{array}$ & $\begin{array}{l}\text { Pseudomonas aeruginosa } \\
\text { Rhodococcus erithropolis } \\
\text { Arthobacter } \mathrm{sp} . \\
\text { Candida bombicola, C. apicola } \\
\text { C. antartica }\end{array}$ \\
\hline Lipopeptides & $\begin{array}{l}\text { Surfactin/iturin/ fengycin } \\
\text { Viscosin Lichenysin Serrawettin } \\
\text { Phospholipids }\end{array}$ & $\begin{array}{l}\text { Bacillus subtilis } \\
\text { P. fluorescens } \\
\text { B. licheniformis } \\
\text { Serratia marcescens } \\
\text { Acinetobacter } \text { sp. } \\
\text { Corynebacterium lepus }\end{array}$ \\
\hline Polymeric surfactants & $\begin{array}{l}\text { Emulsan } \\
\text { Alasan Liposan Lipomanan }\end{array}$ & $\begin{array}{l}\text { Acinetobacter calcoaceticus } \\
\text { A. radioresistens } \\
\text { C. lipolytica } \\
\text { C. tropicalis }\end{array}$ \\
\hline $\begin{array}{c}\text { Particulate } \\
\text { Biosurfactants }\end{array}$ & $\begin{array}{l}\text { Vesicles } \\
\text { Whole microbial cells }\end{array}$ & $\begin{array}{l}\text { A. calcoaceticus } \\
\text { Cyanobacteria }\end{array}$ \\
\hline
\end{tabular}

\section{Properties of Biosurfactants}

Biosurfactants are of increasing interest for commercial use because of the continually growing spectrum of available substances. There are many advantages of Biosurfactants compared to their chemically synthesized counterpart. The main distinctive features of biosurfactants and a brief description of each property are given below.

- Surface and interface activity

- Temperature, $\mathrm{pH}$ and ionic strength tolerance

- $\quad$ Biodegradability

- Low toxicity

- $\quad$ Emulsion forming and emulsion breaking

- Antimicrobial activity

\section{Potential Applications of Biosurfactants in Food Processing}

Biosurfactant properties are of interest to a wide range of industrial fields, from petroleum to pharmaceuticals. In the food industry, these microbial compounds exhibit useful properties as emulsifiers (Banat et al. 2000), antiadhesive, and antimicrobial agents (Singh and Cameotra 2004). Currently, some products based on biosurfactants can be found in the international market, such as PD5R (Pendragon Holdings Ltdwww.pd-5england.co.uk), sold as a fuel additive based on a biosurfactant blend of rhamnolipid and enzymes; EC-601R (EcoChem Organics Co-www.ecochem.com), commercialized as a water insoluble hydrocarbon dispersant, JBRR products (Jeneil Biosurfactant Company), rhamnolipids in aqueous solutions with different purity levels or in a semisolid form, and the Rhamnolipid Inc. products (Rhamnolipid Holdings - www.rhamnolipidholdings.com), among others. Nowadays, the rhamnolipids from P. aeruginosa are the most promising class of biosurfactants, since the U.S. Environmental Protection Agency has approved rhamnolipids for the use in food products, cosmetics, and pharmaceuticals (Nitschke and Costa 2007). 


\section{Biosurfactants as Food Additives}

The basic purpose behind processing food is not only to make it safe to eat at a later date, but also to make it look, taste, and smell as enticing and as close to freshly prepared as possible. Much of the availability, convenience, and variety that people enjoy in their food supply are due to food processing that often uses specific ingredients to maintain the final product quality. Since food that does not taste, look, or smell good will not be eaten, food additives are essential ingredients in our food supply.

The particular combination of characteristics such as emulsifying, anti adhesive, and antimicrobial activities presented by biosurfactants suggests their application as multipurpose ingredients or additives. The development of these biomolecules should represent, in the near future, an increasing significant part of the market for food additives.

\subsection{Emulsifiers}

Food makers use emulsifiers to reduce the surface tension between two immiscible phases at their interface allowing them to mix (Shepherd et al. 1995). Commercially available emulsifiers used in the food and drink sectors comprise two main types, lecithin, derived from soy and egg, and a range of other emulsifiers produced primarily from synthetic sources. The fast growth of functional foods market requiring natural or organic ingredients represents an opportunity for new emulsifiers. Considering that biosurfactants exhibit surface-active and emulsifier action, there is a great potential market for effective biosurfactants in the food industry not only due to their surface activity, but also for their environmental friendly nature (Mohan et al. 2006), low toxicity (Flasz et al. 1998), their unique structures and properties, and the increasing customer demand for natural or organic over synthetic ingredients.

\subsection{Antimicrobial Agent}

A wide range of biosurfactants has shown antimicrobial activity against bacteria, yeast, fungi, algae, and viruses (Nitschke and Costa 2007). Among biosurfactants, lipopeptides form the widely reported class having antimicrobial action. The genus Bacillus is responsible for producing the most well-known lipopeptides biosurfactants. B. subtilis produces the first biosurfactant presenting this antimicrobial property, that is, surfactin (Das et al. 2008, Fernandes et al. 2007). It also produces other lipopeptides with the same property: fengycin, iturin, bacillomycins, and mycosubtilins (Das et al. 2008).

\subsection{Antiadhesive Agent}

It is important to review some concepts to understand why one would use the antiadhesive properties of biosurfactants in the food industry. Usually, in nature, bacteria do not stand as alone cells, but they organize themselves as communities, which may be more or less structuralized. Rodrigues et al. (2004) studied the influence of two biosurfactants produced by probiotic bacteria (Lactococcus lactis and Streptococcus thermophilus) biofilms development by S. epidermidis, St. salivarius, S. aureus, Rothia dentocariosa, C. albicans, and $C$. tropicalis in voice prostheses. Both biosurfactants showed antimicrobial activity but, depending on the microorganism, they presented different effective concentrations.

Surfactants provide multifunctional properties for food additives as emulsifiers, dispersants, wetting agents and solubilizers in foods which contain fats and oils such as baked goods, dairy foods, salad dressings, shortenings and margarine.

\section{Conclusion}

In recent years, many of these biochemically obtained compounds and their production processes have been patented, but only some of them are commercialized. The profitable production of biosurfactants is determined by some factors, such as the raw material costs, the availability of an economic and suitable production procedure, and the product yield of microorganisms. Thus, one can use cheaper or even waste substrates, with engineered strains, and carry out efficient bioprocesses achieve an economic process for biosurfactant production. The use of engineered strains could be a problem when producing additives for the food industry, due to approval issues, so the problem is reduced to the search for low-cost raw materials and the process scale-up.

In conclusion, the biosurfactant market tends to increase as the screening programs reveal new microbial strains showing novel molecules with unusual properties, and the search for low- cost raw materials and improved strategies for the processes scaleup provide successful results. 


\section{References}

[1]. Das, P., Mukherjee, S., and Sen, R. 2008. Antimicrobial potential of a lipopeptide biosurfactant derived from a marine Bacillus circulans. J. Appl. Microbiol. 104:1675-1684.

[2]. Flasz, A., Rocha, C. A., Mosquera, B., and Sajo, C. 1998. A comparative study of the toxicity of a synthetic surfactant and one produced by Pseudomonas aeruginosa ATCC 55925. Med. Sci. Res. 26:181-185.

[3]. Jenkinson, H. F. and Lappin-Scott, H. M. 2001. Biofi lms adhere to stay. Trends Microbiol. 9:9-10.

[4]. Nitschke, M. and Costa, S. G. V. A. O. 2007. Biosurfactants in food industry. Trends Food Sci.Tech. 18:252-259.

[5]. Nitschke, M. and Pastore, G. M. 2003. Evaluation of agroindustrial wastes as substrates for biosurfactant production by Bacillus. Revista Biotecnologia Ciência \& Desenvolvimento 31:63-67 (in Portuguese).

[6]. Nitschke, M. and Pastore, G. M. 2006. Production and properties of a surfactant obtained from Bacillus subtilis grown on cassava wastewater. Bioresource Technol. 97:336-341. 